\title{
Corrigendum
}

\section{Evaluation of the effectiveness of stainless steel cooking pots in reducing iron-deficiency anaemia in food aid-dependent populations - Corrigendum}

Leisel Talley, Bradley A Woodruff, Andrew Seal, Kathryn Tripp, Laurent Sadikiel Mselle, Fathia Abdalla, Rita Bhatia and Zhara Mirghani

doi:10.1017/S1368980009005254, Published online by Cambridge University Press 01 Apr 2009

Co-author names are correct as follows:

Kathryn Tripp should be Katherine Tripp

Zhara Mirghani should be Zahra Mirghani

The copyright line for this article should read:

(C) The Authors 2009. The contribution by Leisel Talley is a work of the US Government and is not subject to copyright protection in the United States.

\section{Reference}

Talley L, Woodruff BA, Seal A, Tripp K, Mselle LS, Abdalla F, Bhatia R and Mirghani Z. Evaluation of the effectiveness of stainless steel cooking pots in reducing iron-deficiency anaemia in food aid-dependent populations. Public Health Nutrition 13(1), 107-115.

\section{Corrigendum}

\section{Acceptability and use of iron and iron-alloy cooking pots: Implications for anaemia control programmes - Corrigendum}

Katherine Tripp, Nancy MacKeith, Bradley A Woodruff, Leisel Talley, Laurent Mselle, Zahra Mirghani, Fathia Abdalla, Rita Bhatia and Andrew J Seal

doi:10.1017/S1368980009005928, Published online by Cambridge University Press 28 May 2009

The copyright line for this article should read:

(C) The Authors 2009. The contribution by Liesel Talley is a work of the US Government and is not subject to copyright protection in the United States.

\section{Reference}

Tripp K, MacKeith N, Woodruff BA, Talley L, Mselle L, Mirghani Z, Abdalla F, Bhatia R and Seal AJ. Acceptability and use of iron and iron-alloy cooking pots: implications for anaemia control programmes. Public Health Nutrition 13(1), 123-130. 